\title{
Deletion analysis of the achaete-scute locus of Drosophila melanogaster
}

\author{
Mar Ruiz-Gómez and Juan Modolell \\ Centro de Biología Molecular, Consejo Superior de Investigaciones Científicas and Universidad Autónoma de Madrid, 28049 \\ Madrid, Spain
}

\begin{abstract}
The achaete-scute gene complex (AS-C) is involved in the development of the central and peripheral (sensory chaetae, sensilla) nervous system. To assess the contribution of the different parts of the complex in the generation of the adult chaetae pattern, we have determined the phenotypes and molecular positions of the breakpoints of 74 terminal deficiencies of the $\mathrm{X}$ chromosome. According to these and previous data, the AS-C is organized, distally to proximally, as follows: the achaete region, with most of its DNA (10 kb) located upstream from the putative achaete (T5) gene; an intermediate region, approximately $18 \mathrm{~kb}$ long, whose deletion only weakly affects the scute function; and the scute region, with most of the DNA critical for its function extending 4-5 kb upstream and $50 \mathrm{~kb}$ downstream of the putative scute (T4) gene. The DNA extending far upstream of the $T 5$ gene and downstream of the $T 4$ gene may provide chromatin conformations adequate for efficient expression of these genes. However, in the case of the T4 gene, the available data suggest the presence of a small number of elements, scattered in the long downstream region, that would respond to topological cues and cis-activate this gene in specific anatomical regions.
\end{abstract}

[Key Words: Terminal deficiencies; achaete-scute complex; Drosophila; chaetae pattern; cis-control]

Received August 10, 1987; revised version accepted September 23, 1987.

The epidermis of insects contains innervated sensory organs (chaetae, sensilla) distributed according to species-specific patterns. In Drosophila, differentiation of these organs depends, both in the larva and the adult, on the activity of the achaete-scute complex (AS-C), which is located at the tip of the $\mathrm{X}$ chromosome (region 1B1-4). Its genetic analysis (García-Bellido 1979) has allowed its subdivision into achaete $(a c)$, scute $(s c) \alpha$, lethal of scute $\left(l^{\prime} s c\right)$, and $s c \beta$ regions (distally to proximally). Recently, the existence of an additional region, proximal to $s c \beta$ and named $s c \gamma$, has been proposed (Dambly-Chaudière and Ghysen 1987; Jiménez and Campos-Ortega 1987).

In the adult, ac mutations remove mostly hairs (microchaetae) and $s c$ mutations affect mostly bristles (macrochaetae). $a c$ and $s c$ mutations complement each other, but pairs of $a c$ or $s c$ mutations complement only partially (García-Bellido 1979). In mitotic recombination clones, deletion of the whole AS-C prevents, with a few exceptions, differentiation of all chaetae and sensilla (García-Bellido and Santamaría 1978). On the other hand, deletion of the l'sc region causes the death of developing cell precursors of the embryonic central nervous system (Jiménez and Campos-Ortega 1979, 1987). Other partial deletions of the complex remove different subsets of larval sensory organs (DamblyChaudière and Ghysen 1987). Taken together, these results indicate that the AS-C is involved in the development of both peripheral and central nervous systems. This conclusion is further strengthened by the expres- sion of the AS-C genes in the neurogenic region of Drosopila embryos (Cabrera et al. 1987; Romani et al. 1987).

The cloning of the AS-C DNA has provided a molecular correlate to the genetic subdivision of the complex (Campuzano et al. 1985). The AS-C occupies at least 90 $\mathrm{kb}$ of DNA located proximally and adjacent to the yellow $(y)$ locus (Fig. 1). The few previously characterized $a c$ mutations (3) map within $5 \mathrm{~kb}$ in the distal part of the complex. An RNA (T5) transcribed from this region is thought to be involved in the $a c$ function. Most of the many $s c$ mutations analyzed (23) are associated with lesions scattered over the proximal $50 \mathrm{~kb}$ of the complex. This DNA spans the proximal $s c \alpha, l^{\prime} s c$, and $s c$ $\beta$ regions (distally to proximally). At least three RNAs are transcribed from these regions. One (T4 RNA) is transcribed from the proximal $s c \alpha$ region and is thought to be most important for the sc function. Another (T3 RNA) is involved in the l'sc function (F. González, S. Romani, M. Ruiz-Gómez, F. Jiménez, and J. Modolell, in prep.). The putative product encoded by the third one (T2 RNA) and its spatial distribution indicate that, most likely, this RNA is irrelevant for nervous system development (F. González, S. Romani, and J. Modolell, unpubl.). The structural genes of the AS-C RNAs are separated by long stretches of DNA. Most $s c$ mutations map within presumably nontranscribed DNA. Long-range cis-perturbations of the expression of the T4 RNA /and perhaps of other transcripts) by the DNA lesions have been invoked to explain the mutant phenotypes (Campuzano et al. 1985). The $s c \gamma$ region, located proximally 


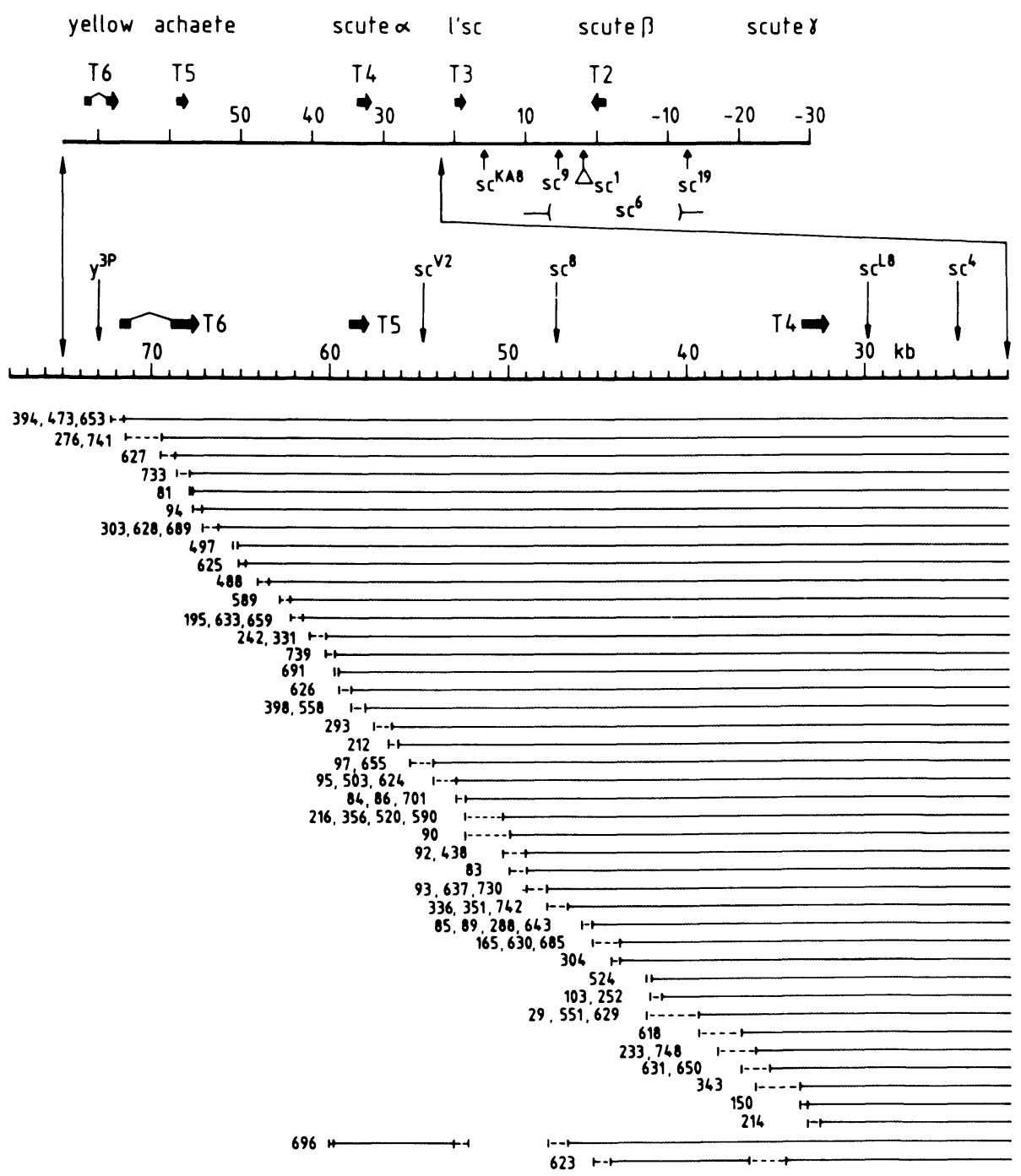

Figure 1. Location of breakpoints of $D f(1) R T$ chromosomes. DNA present in each deficiency is represented by a continuous line under the achaete-scute system of coordinates (Campuzano et al. 1985). Dashed lines represent the uncertainty in the location of the breakpoints. On top of the figure, a simplified physical map of the AS-C is represented, indicating its major subdivisions. Location of breakpoints of several inversions, $T(1 ; 2) s c^{19}, s c^{1}$ (a gypsy insertion), and the $s c^{6}$ deletion are indicated above the coordinate line or on the simplified map of the AS-C. Thick horizontal arrows indicate the regions where transcripts T2-T6 arise. Location of the T6 (yellow) gene is according to Chia et al. (1986) and to our unpublished observations. Several embryonic transcripts arising from the region comprised between the T5 and T6 genes (Campuzano et al. 1985; Chia et al. 1986) and another transcript arising from the scute $\gamma$ region are being characterized in our laboratory and have not been indicated. Transcription of the T4 gene starts approximately 160 bp to the right of an XhoI site at coordinate 33.4 (Villares and Cabrera 1987). The most proximal deficiency (214) has the breakpoint within $0.7 \mathrm{~kb}$ to the right of this $X h o \mathrm{I}$ site. All the RT deficiencies mapped are $\mathrm{y}^{-}$.

from the $s c^{19}$ breakpoint (Fig. 1), is important for the development of the larval sensory organs (Dambly-Chaudière and Ghysen 1987), but appears to have little bearing on the development of the adult chaetae pattern |García-Bellido 1979; Campuzano et al. 1985; our unpubl. data).

In this work, we have carried out a deletion analysis of the distal part of the AS-C, with the aim of defining the role(s) of its long untranscribed regions. More specifically, we wanted to address the question as to how the topological distribution of the ac and sc functions is encoded in the AS-C DNA. The results indicate that part of the untranscribed regions may have a structural role in providing favorable chromatin conformations for T4 and T5 gene expressions. Moreover, they suggest the presence in regions downstream and far removed from the $\mathrm{T} 4$ gene of elements controlling its spatial expression.

\section{Results}

\section{Molecular mapping of RT deficiencies}

A set of 74 terminal deficiencies of the $\mathrm{X}$ chromosome (Df(1)RT; Mason et al. 1984, 1986) whose phenotypes indicated that they had breakpoints within the $y$ locus 
or the distal part of the AS-C have been used in this work. Their breakpoints, determined by Southern blot analyses, are evenly distributed over $40 \mathrm{~kb}$ of DNA, from the $y$ locus to the T4 gene (Fig. 1 and Table 1). The most proximal deficiency (214) lacks, at least, the majority of the T4 gene $5^{\prime}$-flanking region or, at most, all the $5^{\prime}$ region and part of the $\mathrm{T} 4$ transcribed sequences. Two deficiencies (696 and 623) had more than one breakpoint within the AS-C.

\section{Phenotypes of the RT deficiencies}

The molecular map obtained indicates that the RT deficiencies should be useful for studying the contribution of the distal part of the AS-C in the generation of the chaetae pattern. Accordingly, we examined the phenotypes of females heterozygous for $D F(1) R T s$ and intercalary deficiencies of the AS-C. In general, RT deficiencies with closely mapping breakpoints had similar phenotypes, suggesting that the probable heterogeneity of the foreign DNA sequences distal to the RT breakpoint did not affect greatly the ac and/or sc phenotypes associated with the RT chromosomes.

The ac phenotypes. We used combinations of the $D f(1) R T s$ with the $D f(1) s c^{19}$, which removes most of the AS-C, or the $\operatorname{In}(1) y^{3 P L} S C^{8 R}$, which is deficient for $y$ and $a c$ but is almost $s c^{+}$(García-Bellido 1979; Campuzano et al. 1985). ac phenotypes were determined by counting the number of microchaetae on the notum and by scoring for the presence of $a c$-sensitive macrochaetae (AVT, PDC, ADC, and PSA, García-Bellido 1979; for macrochaeta nomenclature, see Fig. 4). Figure 2 shows phenotypes of RT deficiencies with breakpoints located in the $y$ gene and the most distal part of the AS-C. The number of microchaetae was a sensitive indicator of amount of ac function. With only a few exceptions, loss of microchaetae correlated linearly with the proximity of the breakpoints to the T5 gene structural sequences. Breakpoints $10 \mathrm{~kb}$ upstream from it, still within the $y$ transcribed region, already showed microchaetae suppression. The ac-sensitive macrochaetae were also affected by breakpoints far removed from the T5 gene (legend to Fig. 2; Fig. 3). In general, the loss of macrochaetae was greater for the deficiencies that mapped closer to the T5 gene, an exception being the AVT macrochaeta that exhibited an erratic pattern of suppression (Fig. 3). Breakpoints in the immediate vicinity of the T5 gene (RT626), or those that removed this gene, caused maximal macrochaetae suppression.

RT deficiencies 242 and 691 were exceptions to the correlation between location of breakpoint and ac phenotype. They mapped closely, the second one having a breakpoint less than $0.9 \mathrm{~kb}$ upstream from the T5 transcribed sequences. Both had relatively weak ac phenotypes.

The wild-type heminotum has approximately $135 \mathrm{mi}$ crochaetae. On its medial region, microchaetae are arranged in four or five longitudinal rows, whereas on the lateral part, the distribution is more irregular, with some
Table 1. Localization within the AS-C of breakpoints of $R T$ deficiencies

\begin{tabular}{|c|c|}
\hline$D f(1) R T$ & Localization on the $\mathrm{DNA}^{\mathrm{a}}$ \\
\hline $394,473,653$ & $\mathrm{H}(72.3)-\mathrm{B}(71.6)$ \\
\hline 276,741 & $\mathrm{Pv}(71.5)-\mathrm{C}(69.5)$ \\
\hline 627 & C (69.5)-Pv(68.7) \\
\hline 733 & $\mathrm{R}(68.6)-\mathrm{Pv}(67.8)$ \\
\hline 81 & $\mathrm{Pv}(67.8)-\mathrm{P}(67.7)$ \\
\hline 94 & $P(67.7)-G(67.2)$ \\
\hline $303,628,689$ & $\mathrm{G}(67.2)-\mathrm{A}(66.3)$ \\
\hline 497 & $\mathrm{G}(65.6)-\mathrm{P}(65.3)$ \\
\hline 625 & P $(65.3)-G(64.8)$ \\
\hline 488 & $\mathrm{X}(64.2)-\mathrm{P}(63.2)$ \\
\hline 589 & $\mathrm{R}(62.9)-\mathrm{X}(62.4)$ \\
\hline $195,633,659$ & $\mathrm{X}(62.4)-\mathrm{G}(61.8)$ \\
\hline 242,331 & $\mathrm{Hc}(61.2)-\mathrm{Hc}(60.3)$ \\
\hline 739 & $\mathrm{Hc}(60.3)-\mathrm{S}(59.9)$ \\
\hline \multirow[t]{3}{*}{696} & $\mathrm{P} \quad(60.2)-\mathrm{S} \quad(59.9)$ \\
\hline & B $(53.2)-S(52.4)$ \\
\hline & B $(47.9)-\mathrm{R}(45.8)$ \\
\hline 691 & $S \quad(59.9)-R(59.7)$ \\
\hline 626 & $\mathrm{R} \quad(59.7)-\mathrm{B} \quad(58.9)$ \\
\hline 398,558 & $\mathrm{~B} \quad(58.9)-\mathrm{P} \quad(58.2)$ \\
\hline 293 & $R \quad(57.6)-R(56.6)$ \\
\hline 212 & $\mathrm{H}(56.8)-\mathrm{S}(56.3)$ \\
\hline 97,655 & B $(55.8)-\mathrm{R}(54.3)$ \\
\hline $95,503,624$ & $\mathrm{R}(54.3)-\mathrm{B}(53.2)$ \\
\hline $84,86,701$ & B $\quad(53.2)-S \quad(52.4)$ \\
\hline $216,356,520,590$ & $\mathrm{~S} \quad(52.4)-\mathrm{B} \quad(50.6)$ \\
\hline 90 & $S(52.4)-G(50.2)$ \\
\hline 92,438 & B $\quad(50.6)-\mathrm{P}(49.4)$ \\
\hline 83 & $\mathrm{G}(50.2)-\mathrm{P}(49.4)$ \\
\hline $93,637,730$ & $\mathrm{P} \quad(49.4)-\mathrm{B}(47.9)$ \\
\hline $336,351,742$ & B $(47.9)-\mathrm{H}(46.8)$ \\
\hline $85,89,288,643$ & $\mathrm{R}(46.0)-\mathrm{H}(45.4)$ \\
\hline $165,630,685$ & $\mathrm{H}(45.4)-\mathrm{H}(43.9)$ \\
\hline \multirow[t]{2}{*}{623} & $\mathrm{H}(45.4)-\mathrm{G}(44.4)$ \\
\hline & $\operatorname{Pv}(36.7)-B \quad(34.4)$ \\
\hline 304 & $\mathrm{G}(44.4)-\mathrm{H}(43.9)$ \\
\hline 524 & $\mathrm{G}(42.3)-\mathrm{B}(42.1)$ \\
\hline 103,252 & B $(42.1)-B(41.5)$ \\
\hline $29,551,629$ & $\mathrm{G}(42.3)-\mathrm{H}(39.5)$ \\
\hline 618 & $\mathrm{H}(39.5)-\mathrm{H}(37.1)$ \\
\hline 233,748 & $\mathrm{X}(38.4)-\mathrm{Pv}(36.3)$ \\
\hline 631,650 & $\mathrm{H}(37.1)-\mathrm{P}(35.5)$ \\
\hline 343 & $\operatorname{Pv}(36.3)-B(33.8)$ \\
\hline 150 & B $(33.8)-\mathrm{O}(33.4)$ \\
\hline 214 & $\mathrm{O}(33.4)-\mathrm{G}(32.7)$ \\
\hline
\end{tabular}

aLocalization, given according to the coordinates of the physical map of the AS-C (Campuzano et al. 1985), was determined in November 1986 for the first 11 deficiencies (not including RT303), in March 1986 for RT233, 748, 343, 150, and 214, and in January-June 1985 for the remaining ones. Restriction site nomenclature is as follows: (A) AvaI; (B) BamHI; (C) ClaI; (G) BglII; (H) HindIII; (Hc) HincII; (O) XhoI; (P) PstI; (Pv) PvuII; (R) EcoRI; (S) SalI; (X) XbaI.

short transversal rows in the vicinity of the intrascutellar suture (Fig. 4). The RT deficiencies showed that this pattern undergoes two types of modifications with decreasing ac function (Fig. 4). The first is a general decrease in the density of microchaetae. The second is a progressive reduction in the area of the notum bearing 
Figure 2. Amounts of T5 RNA in 0- to 1-day-old pupae in several combinations $D f(1) R T / \operatorname{In}(1) y^{3 P L} S C^{8 R}(\triangle)$ and number of microchaetae on the notum of combinations $D f(1) R T / \operatorname{In}(1) y^{3 P L} S c^{8 R}$ $(O)$ and $D f(1) R T / D f(1) s c^{19}(0)$. One hundred percent represents: the amount of T5 RNA found in 0- to 1-day-old heterozygous Oregon $\mathrm{R} / \operatorname{In}(1) \mathrm{y}^{3 P L} S C^{8 R}$ control females; the number of microchaetae on the heminotum of females of genotypes wild-type Canton $S / I n(1) y^{3 P L} S C^{8 R}(120.1 \pm 5.6$, not including the humeral microchaetae) and wild-type Vallecas/Df(1)sc ${ }^{19}$ (123.4 \pm 3.7 , including the humerals). Canton $\mathrm{S} / \operatorname{In}(1) y^{3 P L} S C^{8 R}$ females had $129 \pm 6$ microchaetae, including the humerals. Homozygous Oregon R, Canton S, and Vallecas females had $135 \pm 2$, including the humerals $(9 \pm 1)$. Standard deviations for the number of microchaetae in the $D f(1) R T / \operatorname{In}(1) y^{3 P L} S C^{8 R}$ and $D f(1) R T / D f(1) s c^{19}$ ranged from 5.3 to 12.6 and 2.3 to 16.8 , the most common values being between 6 and 8 , and 4 and 8 , respectively. Dorsocentral macrochaetae were affected in the combinations of $\operatorname{In}(1) y^{3 P L} S C^{8 R}$ with the $R T 733(18 \%$ of heminotums), 81 (33\%), $94(44 \%)$, 628 (58\%), 689 (35\%), 303 (53\%), and all the remaining more proximal deficiencies. PSA macrochaeta was affected in RT303 and all the more proximal ones. Positions of several deficiency breakpoints do not coincide with those shown in Fig. 1 and Table 1, since phenotypes were determined and the breakpoint positions reexamined $\sim 1.5 \mathrm{yr}$ after the original localization. Determination of the phenotypes represented by filled symbols was performed 5-7 months before the determination of the breakpoints; therefore, their position on the DNA coordinate is only approximate. Positions of T6 and T5 transcribed sequences are indicated. When two or three deficiency breakpoints share the same location, the microchaetae symbol with the largest ordinate corresponds to the top RT identifying number, the second symbol to the second number, and so on. The homozygous $\operatorname{In}(1) y^{3 P L} S c^{8 R}$, although deficient for $a c$, differentiates $40 \%$ as many microchaetae as the wild type (Fig. 6). Originally this deficiency was an extreme ac mutant. The accumulation of modifiers has led to a partial replacement of the missing ac function, probably by the $s c$ function. This may explain that RT deficiencies lacking most or all of the $a c$ function show more moderate ac phenotypes in combination with the $\operatorname{In}(1) y^{3 P L} S c^{8 R}$ than with the $D f(1) s c^{19}$.

microchaetae. Thus, the weakest mutations affect only the area surrounding the DC macrochaetae at the posterior third of the notum. The next area affected is the anterior and central part of the notum. In more extreme mutations, microchaetae appear only in the central area of each heminotum.

The sc phenotypes. These phenotypes were determined for all the $D f(1) R T$ s except the 11 more distal ones by scoring for the presence of macrochaetae on the head and notum. When two or more deficiencies had their breakpoints within the same restriction fragment and had similar phenotypes, only the phenotype of the most viable combination will be shown. Phenotypes were determined in $D f(1) R T / D f(1) s c^{19}$ combinations (Fig. $3)$ or, if these were lethal, in combinations with $\operatorname{In}(1) s c^{8 L} s c^{4 R}$ or $\operatorname{In}(1) s c^{L 8 L} s c^{9 R}$ (Fig. 5). It should be stressed that $\operatorname{In}(1) s c^{L 8 L} s c^{9 R}$, although a strong $s c$ mutant, still has some sc function. For the sake of comparison, the phenotypes of some RT deficiencies that were viable in combination with $D f(1) s c^{19}$ or $\operatorname{In}(1) s c^{8 L} s c^{4 R}$ are also shown over the $\operatorname{In}(1) s c^{8 L} S c^{4 R}$ or $\operatorname{In}(1) s c^{L 8 L} S c^{9 R}$.

Deficiencies mapping most distally caused, at the most, extremely weak sc phenotypes (Fig. 3). Similar phenotypes were observed with the control combination $+/ D f(1) s c^{19}$ (not shown). The majority of more proximal deficiencies (mapping between coordinates 55 and 38) showed significant but weak sc phenotypes (Figs. 3 and 5 ); those with breakpoints within $4-5 \mathrm{~kb}$ from the T4 gene transcriptional start caused intermediate or strong sc phenotypes. Surprisingly, most phenotypes of combinations with the $\operatorname{In}(1) s c^{8 L} S c^{4 R}$ were stronger than those

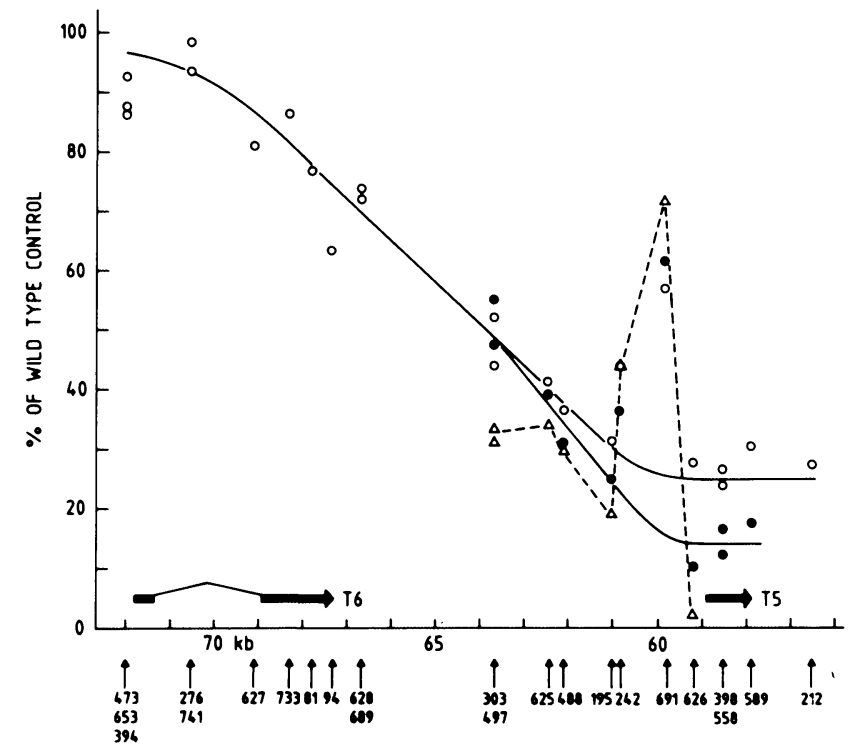

with the $D f(1) s c^{19}(R T 630,304,524,629,618$, and 631). This effect was especially noticeable with the ANP, PS, and PNP macrochaetae. It suggests that the phenotypes of the RT deficiencies can be modified by the homolog chromosome, even if this is $s c^{-}$, or by the genetic background.

The $\operatorname{In}(1) s c^{8 L} s c^{4 R}$ has an apparently intact $a c$ region that does not fully support development of $a c$-sensitive macrochaetae (AVT, PDC, ADC, and PSA), probably due to variegation of the $s c^{8}$ breakpoint (Fig. 5). RT deletions deficient for the $a c$ region partially or completely rescued the AVT and A/PDC macrochaetae, suggesting that their development can be mediated by both ac and sc functions. This interpretation is reinforced by the partial removal of $\mathrm{A} / \mathrm{PDC}$ macrochaetae in combinations of $\operatorname{In}(1) s c^{L 8 L} s c^{9 R}$ with $D f(1) R T s$ that are relatively strong $s c$, but not with those that are weak $s c$ (Fig. 5).

\section{Abundance of T5 RNA in Df(1)RT pupae}

The $\mathrm{T} 5$ gene has been directly implicated in the ac function (Campuzano et al. 1985, 1986). As a measure of its activity in RT deficiencies, we have determined the abundance of T5 RNA in 0- to 1-day-old pupae of combinations $D f(1) R T / \operatorname{In}(1) y^{3 P L} S c^{8 R}$. (This stage of development coincides with a maximum of T5 RNA accumulation.) Figure 2 shows that RT deficiencies with ac phenotypes have decreased abundances of T5 RNA and that there is a positive correlation between abundance of $\mathrm{T} 5$ RNA and number of microchaetae on the notum. 


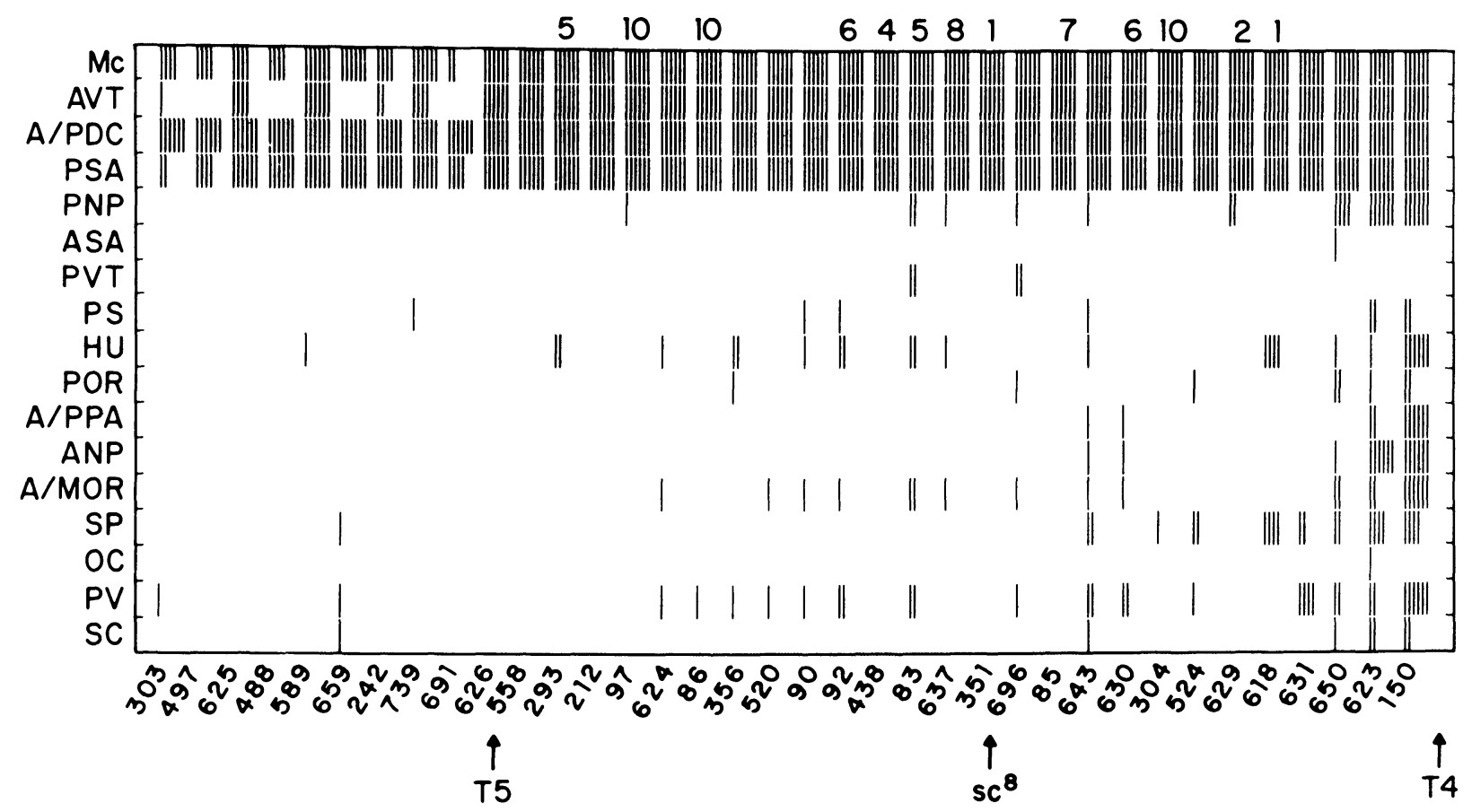

Figure 3. Phenotypes of the $D f(1) R T / D f(1) s c^{19}$ combinations. The standard nomenclature for each macrochaeta is used (see Fig. 4). (Mc) microchaetae. The bars indicate that the corresponding macrochaeta is absent in <10\% (I), 10-39\% (I\|), 40-69\% (I\|I), or $70-100 \%(||||||)$ of the heminotums or half heads. Twelve macrochaetae are grouped in six pairs (A/PDC, HU, A/PPA, A/MOR, SP, and $\mathrm{SC})$. For these macrochaetae $100 \%$ represent the complete absence of both members of the pair. For Mc, the same symbols represent percent of suppressed microchaetae. Some combinations had poor viability. In these cases, the number of flies examined, if less than 12 , is indicated on top of the corresponding phenotype. $D f(1) R T s$ are ordered according to the position of their breakpoints on the DNA (Fig. 1). The phenotype of $R T 150$ was obtained from dead pharate adults removed from the puparium. $D f(1) R T 685$, not shown, has a breakpoint at coordinate 45 , and, remarkably, a very weak ac phenotype and many extrachaetae in ectopic positions (Hairy-wing phenotype, not shown). The analysis of this deficiency will be presented elsewhere. Approximate locations of T5 and T4 genes and In(1) $s c^{8}$ breakpoint are indicated.

\section{Interactions between $\mathrm{Df}(1) \mathrm{RT}$ and $\mathrm{h}^{1}$ or $\mathrm{emc}^{\mathrm{pel}}$}

It has been shown that loss-of-function mutations at the hairy $(h)$ and extramacrochaetae (emc) loci promote an excess of function of the AS-C, with the generation of supernumerary chaetae on ectopic positions (Moscoso del Prado and García-Bellido 1984a,b). To identify AS-C regions important for these interactions, we examined the effects of homozygous $h^{1}$ and $e m c^{\text {pel }}$ mutations on the phenotypes of $D f(1) R T S / D f(1) y^{3 P L} s^{8 R}$. The analysis was restricted to the ac region (Fig. 6). $h^{1}$ did not significantly affect the phenotype of the control $D f(1) y^{3 P L} S^{3 R}$ (see also Moscoso del Prado and García-Bellido 1984a), but partially rescued the ac phenotype of most RT defi-

Figure 4. Chaetae positions on the heminotum of females heterozygous for the $\operatorname{In}(1) y^{3 P L} S c^{8 R}$ and a wild type (Canton $S$ ) or a $D f(1) R T$ chromosome. Small dots and empty circles represent positions of micro- and macrochaetae, respectively. Patterns have been drawn after photographs of a typical individual of the indicated genotype. The central longitudinal rows are more apparent on the fly due to the anterior-posterior tilt of microchaetae. Macrochaeta nomenclature, as described in Lindsley and Grell (1968) or García-Bellido (1979), is indicated. The breakpoint position for RT497 is that indicated in Fig. 2; that for $R T 739$ was to the right of the T5 gene, making this deficiency null for $a c$ but $s c^{+}$. RT214 is a strong $s c$. ciencies. $e m c^{\text {pel }}$ had a larger rescuing effect, which was more pronounced, in absolute number of microchaetae, when some ac function remained; rescuing included the
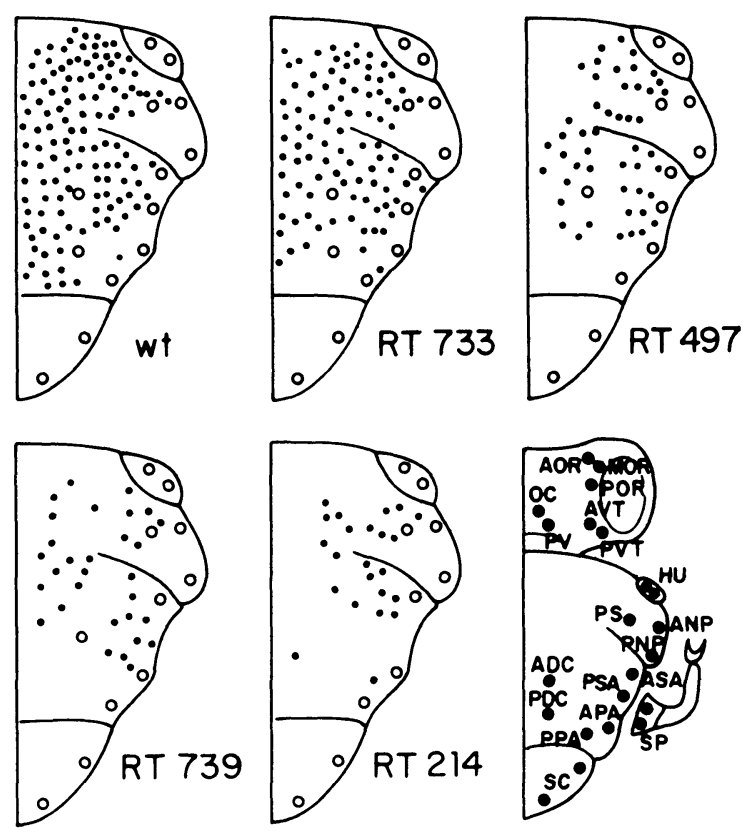

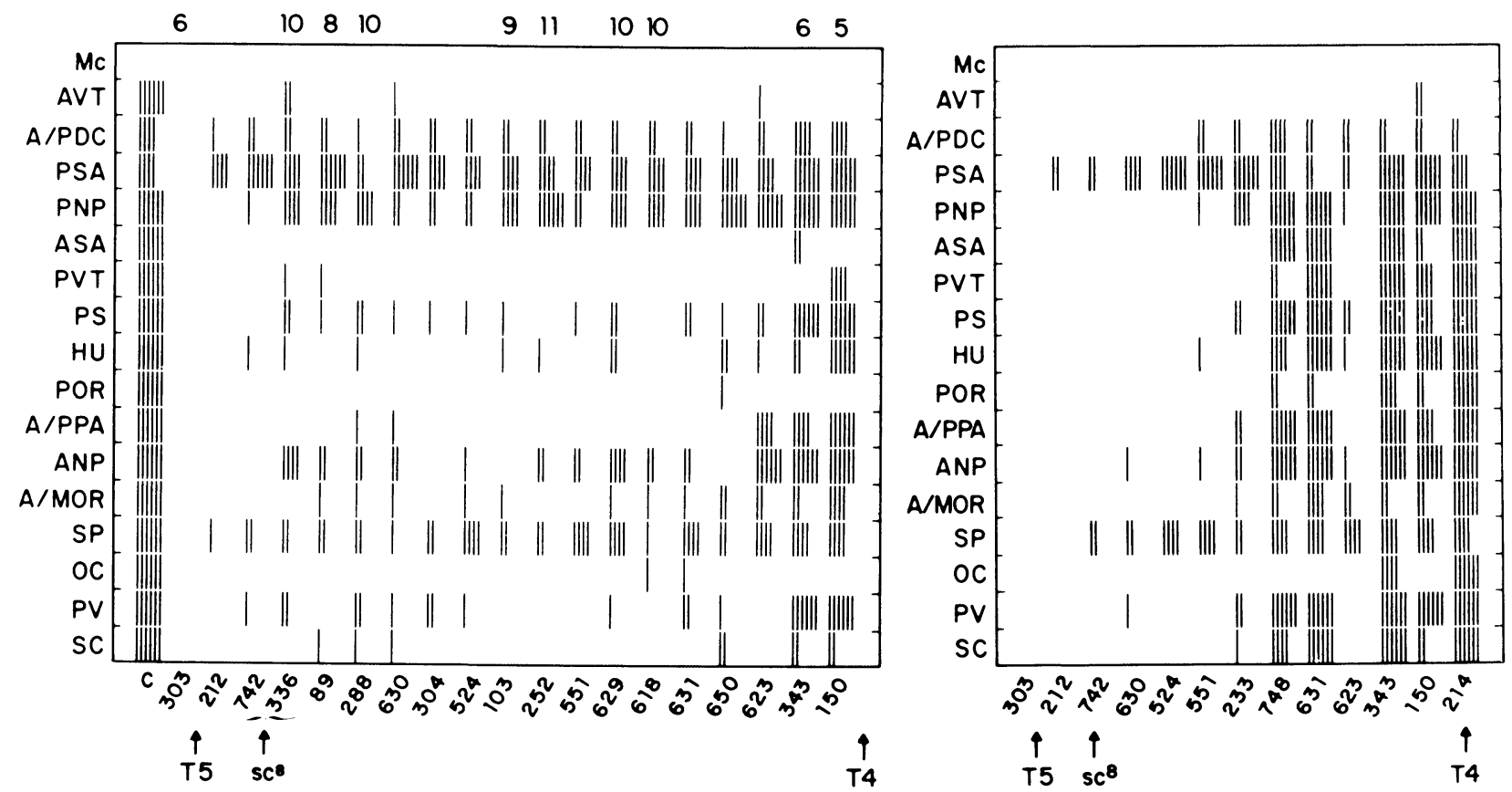

Figure 5. Phenotypes of the combinations $D f(1) R T / \operatorname{In}(1) s c^{8 L} s c^{4 R}$ (left panel) and $D f(1) R T / \operatorname{In}(1) s c^{L 8 L} s c^{9 R}$ (right panel). Symbols and nomenclature are as in Fig. 2. (C) Phenotype of pharate male flies $I n(1) s c^{8 L} s c^{4 R}$ dissected from the puparium. Deficiencies $R T 89,103$, $150,214,233,252,288,336,343,551$, and 748 were lethal in combination with $D f(1) s c^{19}$. The lethality was not due to the lack of $l^{\prime} s c$ function; all were viable over the $\operatorname{In}(1) s c^{L 8 L} S c^{9 R}\left(1^{\prime} s c^{-}\right)$. Deficiencies 233, 748, and 214 were lethal in combination with the $\operatorname{In}(1) s c^{8 L} s c^{4 R}$.

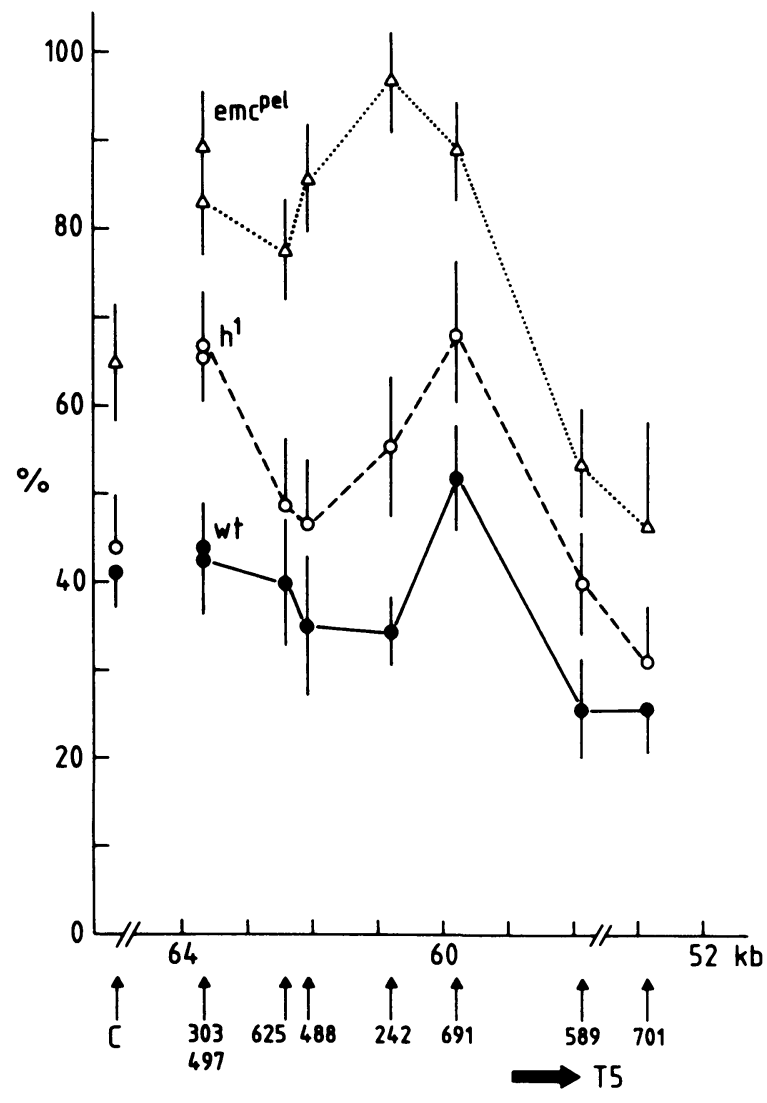

control $a c^{-}$deficiency. Thus, the $a c$ region distal from the breakpoint of $R T 691$ can be deleted without impairing the $h^{1}$ and $e m c^{p e l}$ effects. (We interpret the small rescue by $h^{1}$ and $e m c^{\text {pel }}$ in the absence of ac function, $R T 589$ and 701 , as mediated by the sc function.) Interestingly, in the combinations of RT691 and 242 with $e m c^{p e l}$, the distribution of microchaetae on the notum was very similar to that of the deficiencies with the weakest ac phenotypes or even to that of the wild type (not shown). This indicates that, under these conditions, most of the region upstream from the T5 gene is unnecessary for the generation of the microchaetae pattern.

\section{Discussion}

The achaete region

One of the goals of this work has been to define molecularly the extent of the $a c$ and distal $s c a$ regions. We have assumed that they extend as far as the locations of breakpoints with ac or sc phenotypes. Evidently, the regions thus defined may not be confined to the DNA con-

Figure 6. Phenotypes of the combinations $D f(1) R T /$ $\operatorname{In}(1) y^{3 P L} S c^{8 R}, \quad D f(1) R T / \operatorname{In}(1) y^{3 P L} S c^{8 R} ; h^{1} / h^{1}, \quad$ and $\quad D f(1) R T /$ $\operatorname{In}(1) y^{3 P L} S c^{8 R} ; e m c^{p e l} / e m c^{p e l}$. One hundred percent represents the number of microchaetae of the wild-type heminotum (135). Positions of RT breakpoints are as indicated (see legend to Fig. 2). (C) Phenotypes of the control homozygous $\operatorname{In}(1) y^{3 P L} S C^{8 R}$ females in combinations with wild type, $h^{1}$ and $e m c^{\text {pel }}$ alleles. 
taining specific regulatory sequences for the ac and sc functions. They may also comprise stretches of chromatin whose structure is a prerequisite for wild-type function but are not regulatory in a strict sense. For example, deficiencies with breakpoints within the $y$ gene have weak ac phenotypes (Fig. 2; RT627, 733, and 81). Thus, in this broad sense, the distal limit of the $a c$ region appears to be within the $y$ gene. [The proximal limit should be contained within the $D p(1 ; Y) s c^{8}$ since this duplication complements the ac phenotypes of RT deficiencies mapping at both sides of the $s c^{8}$ breakpoint (Ruiz-Gómez 1986).]

In general, the ac phenotypes of the RT deficiencies are stronger the more ac DNA they eliminate. RT242 and 691 are exceptions: they have ac phenotypes weaker than those of deficiencies with neighboring breakpoints. Possibly, the adjacent foreign DNA somehow enhances the ac function. However, the close proximity of the 242 and 691 breakpoints suggests alternative explanations. For instance, the deletions may have eliminated distal DNA sequences that depress ac function; or the chromatin structure of the remaining ac region is more favorable for ac function than that adopted by more complete but still truncated $a c$ regions.

\section{Role of the ac upstream region}

We have proposed that the T5 gene is directly implicated in the ac function (Campuzano et al. 1985). Consistent with this proposal, the amounts of T5 RNA are decreased in $D f(1) R T s$ and correlate roughly with the number of microchaetae on the notum (Fig. 2). Thus, the interference of $D f(1) R T s$ with ac function is probably mediated by a decreased expression of the T5 gene. On the other hand, the gradual decrease of ac function with increasing removal of the DNA comprised between 10 and $2 \mathrm{~kb}$ upstream from the T5 gene suggests that most of this DNA is somehow relevant for the ac function, the deletion analysis having failed to single out one or a few subregions as especially important. However, the very weak ac phenotypes of the combinations $D f(1) R T 242$ or $691 / \operatorname{In}(1) y^{3 P L} S c^{8 R}{ }^{8} e m c^{p e l}$ indicate that under some conditions, most or all of this DNA is dispensable. Only $0.9 \mathrm{~kb}$ of $5^{\prime}$ sequences flanking the T5 gene (RT691) are sufficient to implement an almost wild-type microchaetae pattern. Thus, most DNA elements controlling the temporal and spatial expression of the T5 gene are probably located within this short 5 ' region or proximally from it. The long region further upstream may provide a chromatin conformation adequate for efficient transcription. A relatively homogeneous distribution of $\mathrm{T} 5$ product might lead to a regular pattern of microchaetae by means of cell interactions (Ghysen and Richelle 1979; García-Bellido 1981). Decreased transcription reveals inhomogeneities in the notum since there is a preferential loss of microchaetae from certain areas (Fig. 4). Thus, the microchaetae pattern probably results from a combination of local requirements for $\mathrm{T} 5$ product and differential activity of the T5 gene, refined by cell interactions. It should be pointed out that a set of overlapping RNAs, found only in embryos, is transcribed from the region between the T5 and T6 (y) genes (Campuzano et al. 1985; Chia et al. 1986; L. Balcells, R. Villares, and J. Modolell, unpubl.). Their spatial distribution seems confined to yolk nuclei/cells (J. Garrell and J. Modolell, unpubl.). These and other properties (our unpubl. results) argue against a role in promoting chaetae development.

\section{The scute region}

The phenotypes of RT deficiencies indicate that the $s c$ region extends approximately $22 \mathrm{~kb}$ to the left of the $\mathrm{T} 4$ structural gene, a gene thought to be most important for the sc function (Campuzano et al. 1985; Villares and Cabrera 1987). Breakpoints in the distal $18 \mathrm{~kb}$ of this region cause weak sc phenotypes at most, and those mapping within 4-5 kb of the T4 gene cause moderate or strong sc phenotypes. Thus, the $s c$ region distal to the $\mathrm{T} 4$ gene may be divisible into two subregions according to the phenotype strength of their respective deletions.

Within the distal $18-\mathrm{kb}$ subregion, there is no correlation between the weak and erratic sc phenotypes and the proximity of the breakpoints to the T4 gene (Fig. 3 and Fig. 5, left panel). Probably the proximity of the breakpoint and/or the telomeric region causes an insufficiency of the sc function. Alternatively, although more unlikely, an element involved in the sc function is located at the distal end of the subregion. Whatever the explanation, this subregion seems relatively unimportant for the sc function.

The proximal subregion, whose deletion causes moderate or strong sc phenotypes, comprises the 4-5 kb immediately upstream from the $\mathrm{T} 4$ gene. This contrasts with the long $(50 \mathrm{~kb})$ downstream $s c$ region defined by most of the previously described $s c$ mutations /Campuzano et al. 1985). A property of these mutations is that the extent of their effect can be measured in the same series of macrochaetae positions affected. That is, macrochaetae can be seriated according to the sensitivity of each chaeta to the $s c$ mutations (García-Bellido 1979). In Figures 3 and 5, macrochaetae are listed following this order of sensitivity, the SC being the most sensitive. Clearly, the sc phenotypes of the RT deficiencies do not fit that series. The HU, PS, and PNP are most sensitive and SC and OC are very resistant to the RT deletions, whereas the opposite occurs with the downstream mapping mutations. Thus, upstream and downstream modifications of the $s c$ DNA affect the spatial distribution of the sc function differently. Two alternatives, or a combination of both, seem the most likely explanations.

\section{Roles of the regions upstream and downstream of the T4 gene}

The first alternative assumes that, by analogy with many other genes, the sequences controlling the temporal and spatial expression of the T4 gene are located in the neighborhood of the transcriptional start. Perturbations of the chromatin conformation by the far down- 
stream lesions would decrease T4 gene expression. Since there is a positive correlation between the strength of the sc phenotype and the proximity to the T4 gene of the DNA lesion (Campuzano et al. 1985), it is assumed that the closer the lesion, the stronger its interference would be. Assuming also that chaeta precursor sites differ in the amounts of T4 gene product required for chaeta differentiation (García-Bellido and Santamaría 1978), a quantitative decrease in T4 product could explain the gradation of sc phenotypes. Due to their proximity the upstream RT breakpoints would interfere more directly with the spatial controlling elements and affect the distribution, as well as the amounts, of T4 product. This could explain their phenotypes not fitting the series of chaeta positions.

The second alternative assumes that cis-acting, sitespecific elements located both $5^{\prime}$ and $3^{\prime}$ from the T4 gene control its spatial expression. The elements would respond to topological cues and activate the $\mathrm{T} 4$ gene by a structural modification or via a product. The downstream mapping $s c$ mutations suggest locations for the 3 ' elements. These mutations can be grouped in four clusters defined by similarity of phenotypes and physical proximity of the lesions (see Fig. 2 of Campuzano et al. 1985). Examples of mutations of each cluster are In(1) $s c^{4}, T(1 ; 3) s c^{K A 8}, s c^{1}$, and $T(1 ; 2) s c^{19}$ (Fig. 1). There would be at least one regulatory element in the DNA corresponding to each cluster, probably in the part most distant from the T4 gene. By interrupting the physical (chromosomal rearrangements) or functional (actively transcribing insertions like gypsy) continuity of the $s c$ DNA, the lesions would impair the cis-activity of the regulatory element and decrease or eliminate $\mathrm{T} 4$ gene transcription in the region(s) of the imaginal disk containing the precursor cells of the affected chaeta(e). The gradation of phenotypes would be due to the progressive removal of consecutive regulatory elements.

This alternative predicts that an internal deletion in the downstream region should only affect the chaetae controlled by the deleted element(s). This is the case for the $s c^{6}$ deletion (Fig. 1). Its phenotype is similar to that of mutations within the same cluster (i.e., $s c^{1}$ ), the most striking difference being that $s c^{6}$ does not affect the SC macrochaetae. Mutations in the rightmost cluster only affect these macrochaetae (i.e., $T(1 ; 2) s c^{19}$ ), suggesting that this cluster contains a scutellar-specific element whose action would not be impaired by the deletion. Unfortunately, no other conveniently located deletions are available to check the generality of the prediction and to help locate the putative control elements.

The following observations also support the second alternative. The $H w^{49 c}$ mutation causes overexpression of the T4 gene and development of many supernumerary macrochaetae; however, such overexpression does not rescue the simultaneous sc phenotype of this mutation due to a breakpoint located between the $s c \alpha$ and $s c \beta$ regions (L. Balcells and J. Modolell, unpubl.; GarcíaAlonso and García-Bellido 1986). Similarly, the excess of function of the AS-C in emc mutants does not rescue the macrochaetae suppressed by sc mutations (Moscoso del
Prado and García-Bellido 1984a,b; García-Alonso and García-Bellido 1986). Thus, lesions in the downstream region cause local, site-specific depletions of sc function that are not compensated by its general overexpression.

Regardless of their physical localization, the spatial controlling sequences might only specify transcription in relatively large but distinct areas of the imaginal disks. Interactions between cells could later refine the pattern of expression (Wigglesworth 1940; Ghysen and Richelle 1979; Moscoso del Prado and García-Bellido 1984b). Evidently, as discussed for the ac pattern, different requirements for amounts of T4 product for chaeta development in distinct areas might also be involved in defining the $s c$-controlled macrochaetae pattern.

\section{Materials and methods}

Drosophila stocks

Seventy-four stocks carrying the $D f(1) R T s$ were a gift of Dr. J. Mason. They were kept as $\mathrm{Df}(1) \mathrm{RT} / \mathrm{y}^{2} s c^{1} Y / C D X$ y $f$. Other stocks used here, described in Lindsley and Grell (1968), are as follows: $\operatorname{In}(1) y^{3 P L} S c^{8 R}, \operatorname{In}(1) s c^{8 L} s c^{4 R} v$ f/In(1)dl-49 y $\mathrm{Hw} \mathrm{m}^{2} \mathrm{~g}^{4}$ $\operatorname{In}(1) s c^{\mathrm{L} 8 \mathrm{~L}} s c^{9 R} s n^{3} w^{a} / \operatorname{In}(1) d l-49$ y $\mathrm{Hw} \mathrm{m}^{2} g^{4}, D f(1) s c^{19} f^{36 / F M 6}$, and $y ; m w h h^{1} . e m c^{p e l}$ is a spontaneous, homozygous viable mutation of the extramacrochaetae locus (Moscoso del Prado and García-Bellido 1984a).

\section{Phenotype scoring}

Unless otherwise indicated, phenotypes were determined in $12-20$ female flies of the indicated phenotypes grown at $25^{\circ} \mathrm{C}$. Presence of macrochaetae on the head and notum was scored. Microchaetae on the notum were counted. Averages and standard deviations were calculated. Since it has been shown $(\mathrm{H}$. Biessmann and L. Mason, in prep.), and we have confirmed, that most RT deficiencies are unstable and gradually lose sequences adjacent to the telomer, phenotypes were determined simultaneously with the position of the breakpoints, except where indicated.

\section{Molecular mapping of breakpoints}

DNA of adult flies heterozygous for an RT deficiency and a partial intercalary deletion of the AS-C $\left[\operatorname{In}(1) \mathrm{y}^{3 P L} S C^{8 R}\right.$ or $\operatorname{In}(1) s c^{8 L} s c^{4 R}$, Fig. 1] was extracted and analyzed in Southern blots using as probes fragments of cloned AS-C DNA covering the intercalary deletion. Five RT deficiencies with breakpoints between the $s c^{8}$ and $s c^{L 8}$ breakpoints were sublethal $\mid R T 748$, 343 , and 150 ) or lethal (233 and 214) over the $I n(1) s c^{8 L} s c^{4 R}$. They were finely mapped using the DNA of heterozygous females $D f(1) R T / y^{2} H w^{U a}$. The $H w^{U a}$ allele has a copia element inserted within the transcribed sequences of the T4 gene (Campuzano et al. 1986). Therefore, the restriction fragments comprising its insertion point (coordinate 32.4 , Fig. 1) are modified in size and, in the Southern blot analyses, could easily be distinguished from the fragments of the RT chromosomes.

\section{RNA preparations}

Third instar female larvae of the indicated genotypes were selected from cultures and allowed to pupate overnight. RNA was extracted in guanidinium isothiocyanate and was purified as previously described (Maniatis et al. 1982; Campuzano et al. 
1986). Quantitation of T5 RNA in total RNA was carried out by an RNase protection method (Campuzano et al. 1986).

\section{Other methods}

Drosophila DNA preparations and genomic Southern blot analyses were performed as described in Carramolino et al. (1982) and Maniatis et al. (1982), respectively.

\section{Acknowledgments}

We are most grateful to A. García-Bellido and F. Jiménez for comments on the manuscript; to J. Mason for providing the collection of RT deficiencies; to H. Biessmann and J. Mason for making available to us their unpublished results; to R. Villares and D. Beamonte for computerizing the phenotypes; and to I. Rodríguez for technical assistance. This work was supported by Comisión Asesora de Investigación Científica y Técnica, Consejo Superior de Investigaciones Científicas (CSIC), and Fondo de Investigaciones Sanitarias. Fellowships from CSIC to M.R.G. are acknowledged.

\section{References}

Cabrera, C.V., A. Martínez-Arias, and M. Bate. 1987. The expression of three members of the achaete-scute gene complex correlates with neuroblast segregation in Drosophila. Cell 50: 425-433.

Campuzano, S., L. Carramolino, C.V. Cabrera, M. Ruiz-Gómez, R. Villares, A. Boronat, and J. Modolell. 1985. Molecular genetics of the achaete-scute gene complex of $D$. melanogaster. Cell 40: 327-338.

Campuzano, S., L. Balcells, R. Villares, L. Carramolino, L. García-Alonso, and J. Modolell. 1986. Excess function Hairy-wing mutations caused by gypsy and copia insertions within structural genes of the achaete-scute locus of Drosophila. Cell 44: 303-312.

Carramolino, L., M. Ruiz-Gómez, M.C. Guerrero, S. Campuzano, and J. Modolell. 1982. DNA map of mutations at the scute locus of Drosophila melanogaster. EMBO I. 1: 11851191.

Chia, W., G. Howes, M. Martin, Y.B. Meng, K. Moses, and S. Tsubota. 1986. Molecular analysis of the yellow locus of Drosophila. EMBO I. 5: 3597-3605.

Dambly-Chaudière, C. and A. Ghysen. 1987. Independent subpatterns of sense organs require independent genes of the achaete-scute complex in Drosophila larvae. Genes Dev. 1: 297-306.

García-Alonso, L. and A. García-Bellido. 1986. Genetic analysis of Hairy-wing mutations. Wilhelm Roux's Arch. Dev. Biol. 195: 259-264.

García-Bellido, A. 1979. Genetic analysis of the achaete-scute system of Drosophila melanogaster. Genetics 91: 491-520.

- 1981. From the gene to the pattern: Chaetae differentiation. In Cellular controls in differentiation (ed. C.W. Lloyd and D.A. Rees), pp. 281-304. Academic Press, London.

García-Bellido, A. and P. Santamaría. 1978. Developmental analysis of the achaete-scute system of Drosophila melanogaster. Genetics 88: 469-486.

Ghysen, A. and J. Richelle. 1979. Determination of sensory bristles and pattern formation in Drosophila. II. The achaete-scute locus. Dev. Biol. 70: 438-452.

Jiménez, F. and J.A. Campos-Ortega. 1979. On a region of the
Drosophila genome necessary for central nervous system development. Nature 282: 310-312.

- 1987. Genes of the subdivision 1B of the genome of Drosophila melanogaster and their participation in neural development. I. Neurogenet. 4: 179-200.

Lindsley, D.L. and E.H. Grell. 1968. Genetic variations of Drosophila melanogaster. Carnegie Institution of Washington, Publ. No. 627.

Maniatis, T., E.F. Fritsch, and J. Sambrook. 1982. Molecular cloning: A laboratory manual. Cold Spring Harbor Laboratory, Cold Spring Harbor, New York.

Mason, J.M., E. Strobel, and M.M. Green. 1984. mu-2 mutator gene in Drosophila that potentiates the induction of terminal deficiencies. Proc. Natl. Acad. Sci. 81: 6090-6094.

Mason, J.M., R.A. Voelker, D. Rosen, A.R. Campos, K. White, and J.K. Lim. 1986. Localization of terminal deficiency breakpoints on the $\mathrm{X}$ chromosome. Dros. Info. Service 63: $164-165$.

Moscoso del Prado, J. and A. García-Bellido. 1984a. Genetic regulation of the achaete-scute complex of Drosophila melanogaster. Wilhelm Roux's Arch. Dev. Biol. 193: 242-245.

. 1984b. Cell interactions in the generation of chaetae pattern in Drosophila. Wilhelm Roux's Arch. Dev. Biol. 193: $246-251$.

Romani, S., S. Campuzano, and J. Modolell. 1987. The achaetescute complex is expressed in neurogenic regions of Drosophila embryos. EMBO J. 6: 2085-2092.

Ruiz-Gómez, M. 1986. Análisis molecular de mutantes del complejo génico achaete-scute de D. melanogaster. Ph.D. thesis. Universidad Autónoma of Madrid.

Villares, R. and C.V. Cabrera. 1987. The achaete-scute gene complex of $D$. melanogaster: Conserved domains in a subset of genes required for neurogenesis and their homology to myc. Cell 50: 415-424.

Wigglesworth, V.B. 1940. Local and general factors in the development of "pattern" in Rhodnius prolixus. I. Exp. Biol. 17: $180-200$. 


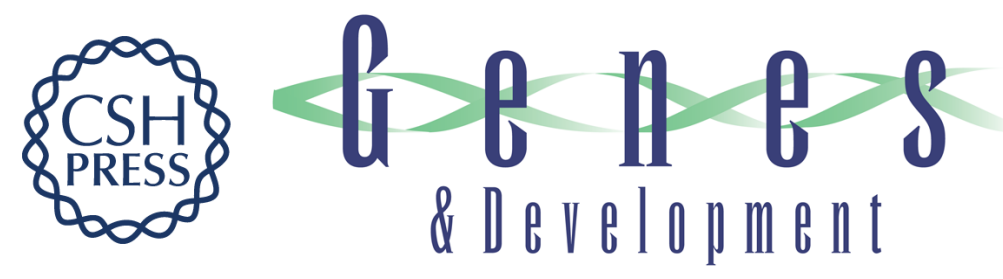

\section{Deletion analysis of the achaete-scute locus of Drosophila melanogaster.}

M Ruiz-Gómez and J Modolell

Genes Dev. 1987, 1:

Access the most recent version at doi:10.1101/gad.1.10.1238

References This article cites 19 articles, 5 of which can be accessed free at: http://genesdev.cshlp.org/content/1/10/1238.full.html\#ref-list-1

License

Email Alerting Receive free email alerts when new articles cite this article - sign up in the box at the top Service right corner of the article or click here.

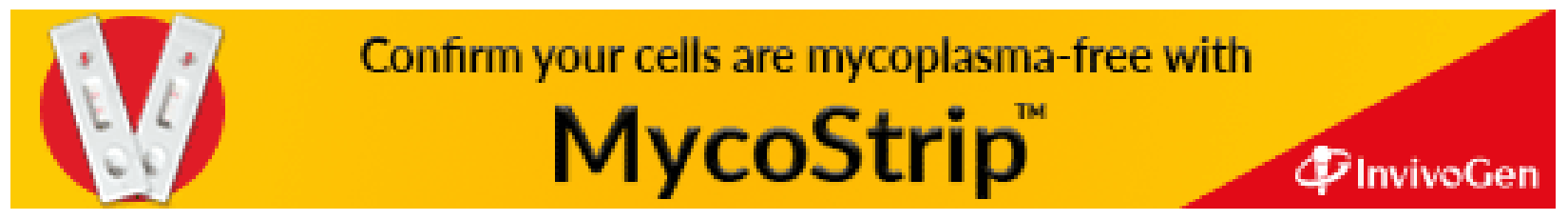

